\title{
Temperature, Moisture, and Fungicide Effects in Managing Rhizoctonia Root and Crown Rot of Sugar Beet
}

\author{
Melvin D. Bolton, Lee Panella, Larry Campbell, and Mohamed F. R. Khan
}

First author: United States Department of Agriculture-Agricultural Research Service (USDA-ARS), Northern Crop Science Laboratory, Fargo, ND; second author: USDA-ARS, Crops Research Laboratory, Fort Collins, CO; third author: USDA-ARS, Northern Crop Science Laboratory, Fargo; and fourth author: Department of Plant Pathology, North Dakota State University, Fargo, and University of Minnesota, St. Paul, MN.

Accepted for publication 31 March 2010.

\begin{abstract}
Bolton, M. D., Panella, L., Campbell, L., and Khan, M. F. R. 2010. Temperature, moisture, and fungicide effects in managing Rhizoctonia root and crown rot of sugar beet. Phytopathology 100:689-697.

Rhizoctonia solani AG-2-2 is the causal agent of Rhizoctonia root and crown rot in sugar beet; however, recent increases in disease incidence and severity were grounds to reevaluate this pathosystem. To assess the capacity at which other anastomosis groups (AGs) are able to infect sugar beet, $15 \mathrm{AGs}$ and intraspecific groups (ISGs) were tested for pathogenicity on resistant ('FC708 CMS') and susceptible ('Monohikari') seedlings and 10-week-old plants. Several AGs and ISGs were pathogenic on seedlings regardless of host resistance but only AG-2-2 IIIB and AG-22 IV caused significant disease on 10-week-old plants. Because fungicides need to be applied prior to infection for effective disease control, temperature and moisture parameters were assessed to identify potential thresholds that limit infection. Root and leaf disease indices were used to evaluate disease progression of AG-2-2 IIIB- and AG-2-2 IV-inoculated plants in controlled climate conditions of 7 to 22 growing degree days (GDDs) per day. Root disease ratings were positively correlated with

occurring at 22 GDDs/day. No disease symptoms were evident from either ISG at $10 \mathrm{GDDs} /$ day but disease symptoms did occur in plants grown in growth chambers set to 11 GDDs/day. Using growth chambers adjusted to 22 GDDs/day, disease was evaluated at $25,50,75$, and $100 \%$ moisture-holding capacity (MHC). Disease symptoms for each ISG were highest in soils with 75 and $100 \%$ MHC but disease still occurred at $25 \%$ MHC. Isolates were tested for their ability to cause disease at 1,4 , and $8 \mathrm{~cm}$ from the plant hypocotyl. Only AG-2-2 IIIB was able to cause disease symptoms at $8 \mathrm{~cm}$ during the evaluation period. In all experiments, isolates of AG-2-2 IIIB were found to be more aggressive than AG-2-2 IV. Using environmental parameters that we identified as the most conducive to disease development, azoxystrobin, prothioconazole, pyraclostrobin, difenoconazole/propiconazole, flutolanil, polyoxin $\mathrm{D}$, and a water control were evaluated for their ability to suppress disease development by AG-2-2 IIIB and AG-2-2 IV 17 days after planting. Flutolanil, polyoxin-D, and azoxystrobin provided the highest level of disease suppression. Because $R$. solani AG-2-2 IIIB and AG-2-2 IV are affected by temperature and moisture, growers may be able to evaluate environmental parameters for optimization of fungicide application.
\end{abstract} increasing temperature of both ISGs, with maximum disease symptoms
Rhizoctonia solani Kühn is a soilborne fungus that causes disease on many economically important crop plants worldwide $(1,35)$. Strains of the fungus are traditionally grouped into genetically isolated anastomosis groups (AGs) based primarily on hyphal anastomosis reactions, and are further subdivided into intraspecific groups (ISGs) (35). $R$. solani AG-2-2 is the main causal agent of Rhizoctonia root and crown rot in sugar beet (Beta vulgaris L.). Infections are typically initiated in the crown but can also begin at or below the soil level. Characteristic circular lesions spread quickly, often coalescing to cover large portions of the root surface (15). Foliar symptoms include severe wilting and chlorosis of leaves, often accompanied by black lesions on the base of the petioles. During the final stages of the disease, leaves remain attached to the crown but collapse onto the soil surface.

Rhizoctonia root and crown rot occurs wherever sugar beet crops are grown $(4,20)$. The disease is estimated as threatening or affecting economic returns of $24 \%$ of the acres sown to sugar beet in the United States and 5 to $10 \%$ in Europe (54). There has been a recent increase in disease incidence and severity in sugar beet production areas in the Red River Valley of Minnesota and North

Corresponding author: M. D. Bolton; E-mail address: Melvin.Bolton@ars.usda.gov

doi:10.1094/PHYTO-100-7-0689

This article is in the public domain and not copyrightable. It may be freely reprinted with customary crediting of the source. The American Phytopathological Society, 2010.
Dakota (3,26). Although a number of $R$. solani AGs are able to colonize sugar beet, AG-2-2 IV is considered the primary cause of Rhizoctonia root and crown rot in most sugar-beet-growing regions of the United States $(11,35,49)$. AG-2-2 IIIB is known better, perhaps, for causing diseases on mat rush, rice, soybean, maize, and edible bean $(20,31,34,48,49)$ but also commonly causes disease in sugar beet $(4,15)$. Although surveys have shown that AG-2-2 IV is more prevalent than AG-2-2 IIIB on sugar beet in the Red River Valley, recent increases in production of crops susceptible to AG-2-2 IIIB such as soybean and maize in conjunction with a decrease in acreage of nonhost crops of AG-2-2 IIIB such as spring wheat (3) are raising concerns that AG-2-2 IIIB is becoming more prevalent in the Red River Valley due to increased inoculum potential. Other than changes in the prevalence of AG2-2 subgroups, it is not known how the recent change in cropping rotations in the Red River Valley may have influenced the frequency and distribution of other AGs and ISGs in the region. The recent increase in disease incidence suggests that a comprehensive evaluation of a wide range of AGs and ISGs that cause significant disease on sugar beet is needed.

Commercial sugar beet cultivars with resistance to Rhizoctonia root and crown rot have been associated with a significant loss in yield potential in the absence of the disease or lack resistance characteristics to other diseases (21). Therefore, growers continue to plant Rhizoctonia-susceptible cultivars and have relied on the application of the strobilurin-class fungicide azoxystrobin to control Rhizoctonia root and crown rot. However, the timing of 
fungicide application is a critical component in Rhizoctonia root and crown rot management. Timing application prior to infection can offer long-term disease protection $(27,50,52)$ and is considered the best approach for managing the risk of resistance to strobilurin fungicides (2). Azoxystrobin is ineffective if applied after plants are infected even if no symptoms are present (53). Knowledge of the environmental parameters that govern $R$. solani infection is a critical aspect in making informed decisions on the timing of fungicide application; however, detailed information on soil moisture and temperature requirements necessary for $R$. solani infection in sugar beet is lacking. Moreover, the heavy reliance on strobilurins to control $R$. solani infections, as well as other sugar beet diseases (45), has raised concerns about fungicide resistance management in sugar beet, especially in areas such as the Red River Valley where the incidence and severity of Rhizoctonia root and crown rot have been increasing. The identification of new control compounds would be critical for disease management in the event that resistance to azoxystrobin develops.

The main objectives of this study were to (i) evaluate pathogenicity of $R$. solani isolates representing several AGs and ISGs on both susceptible and resistant sugar beet germplasms at two different plant growth stages, (ii) determine environmental parameters (temperature and moisture) that are minimally necessary as well as most conducive for infection, and (iii) evaluate the efficacy of fungicides from several chemical classes to control Rhizoctonia root and crown rot under conditions optimized for $R$. solani infection.

\section{MATERIALS AND METHODS}

Plant and fungal material. For the evaluation of $R$. solani AG and ISG pathogenicity of sugar beet, the sugar beet lines 'Monohikari' and 'FC708 CMS' were used (17). Monohikari is a diploid, $R$. solani-susceptible, commercial hybrid with monogerm seed. FC708 CMS is a diploid, $R$. solani-resistant, genetic-cytoplasmic male sterile (CMS) female germplasm with monogerm seed. All R. solani cultures were paired with known AG test cultures maintained in cryogenic storage on sterilized barley grains as described (34). After AG or ISG confirmation, isolates of $R$. solani representing 15 AGs or ISGs $(37,40)$ were grown on potato dextrose agar (PDA) for 7 days and then transferred to a sterile barley medium $\left(100 \mathrm{~cm}^{3}\right.$ of barley and $60 \mathrm{ml}$ of distilled water autoclaved at $120^{\circ} \mathrm{C}$ for $75 \mathrm{~min}$ ) and allowed to grow for 2 weeks. The 2-week-old cultures were removed from the flasks and air dried for 2 days. The dried, infested barley was ground in a blender and stored in bags at $4^{\circ} \mathrm{C}$ until use.

For growth chamber studies, sugar beet seed of 'Beta-1305' (Betaseed, Shakopee, MN) and R. solani AG-2-2 IIIB and AG-2-2 IV were used. Beta-1305 is a diploid, $R$. solani-susceptible, commercial hybrid. Isolates of $R$. solani AG-2-2 IIIB and AG-2-2 IV recovered from sugar beet grown in the Red River Valley were obtained from Dr. Carol Windels (University of Minnesota). These isolates were produced in bulk as described by Kirk et al. (28), except that sterilized barley was used in place of millet seed.

Molecular characterization. To test the ability of PCR to discriminate AG-2-2 IIIB and AG-2-2 IV, genomic DNA was isolated from mycelium scraped from the surface of PDA plates using the DNeasy Plant Mini kit (Qiagen) and used in a polymerase chain reaction (PCR) with primers P-22-IV (6) that are AG-2-2 IV specific and primers MDB-034 (5'-AGGCAGA GACATGGATGGGAG-3') and MDB-035 (5'-CCTTGGCCA MCCTTTTTAT- $3^{\prime}$ ) that were designed to be AG-2-2 IIIB specific. Primers MDB-034 and MDB-035 are similar to previously published primers P-22-IIIB (6). However, P-22-IIIB primers did not provide reliable discrimination in our laboratory using previously identified conditions (6); therefore, they were slightly modified to alleviate unnecessary degeneracy and to take better advantage of single nucleotide polymorphisms between AG-2-2
IIIB and AG-2-2 IV rDNA sequence data retrieved from the National Center for Biotechnology Information. To identify the optimal conditions that allow for discrimination between AG-2-2 IIIB and AG-2-2 IV, gradients of $\mathrm{MgCl}_{2}$ (1.5 to $3.5 \mathrm{mM}$ final concentration) and annealing temperature $\left(50\right.$ to $\left.68^{\circ} \mathrm{C}\right)$ were used in standard PCR reactions using the AmpliTaq DNA polymerase and GeneAmp PCR buffer system (Applied Biosystems) following the manufacturer's instructions. Products were visualized on a $1 \%$ (wt/vol) Tris-borate-EDTA agarose gel. The isolates were further tested for ISG by differential growth on PDA plates at $35^{\circ} \mathrm{C}$ as described by Brantner and Windels (3).

Analysis of $R$. solani AG or ISG pathogenicity to sugar beet seedlings. This experiment was conducted to study the effects of isolate, plant type, and the interaction of isolate-plant type on seedling emergence. To ensure that the inoculum load was similar among the $R$. solani isolates in pathogenicity assays, colony forming units (CFU) were determined for each isolate. To calculate $\mathrm{CFU}$, three $10 \mathrm{-mg}$ samples of ground barley inoculum were placed onto individual plates of PDA and incubated at $23^{\circ} \mathrm{C}$. After $18 \mathrm{~h}$, the number of CFU was counted. Dried, steam-pasteurized soil was mixed with either $R$. solani-infested barley for a final rate of $0.4 \mathrm{CFU} \mathrm{\textrm {g } ^ { - 1 }}$ of soil or ground sterilized barley as a control. Clay pots $(10 \mathrm{~cm}$ in diameter) were filled with $250 \mathrm{~g}$ of the soil mix. Then, 25 surface-disinfested seed of susceptible Monohikari or resistant FC708 CMS were planted in each pot. In each of two runs, two pots representing each plant type (resistant or susceptible) by isolate (15 AGs or ISGs and mock-inoculated control) combination were used. The proportion of emergence (out of $n=$ 25) from each pot was transformed using the arcsine square root transformation to normalize the data. The data were fitted to a linear mixed model according to a two-way (isolate, plant type, and interaction of isolate-plant type) randomized complete block experiment with two blocks (runs) using PROC MIXED (SAS 9.1; SAS Institute Inc., Cary, NC). Blocks, the interaction of blocks-plant type, and the interaction of blocks-isolates were assumed to be random effects. Dunnett's one-tailed test $(P=0.05)$ was used to identify isolates that reduced emergence compared with the control.

Analysis of $R$. solani AG or ISG pathogenicity to 10 -weekold sugar beet plants. Five seeds from susceptible Monohikari or resistant FC708 CMS were planted into dried, steam-pasteurized soil in 15.2-cm-diameter pots. Plants were watered and fertilized as needed and each pot was thinned to one healthy plant after seedling establishment. Ten weeks after planting, soil was carefully pulled away to expose one side of the root $\approx 2.5 \mathrm{~cm}$ below the soil surface, and $0.62 \mathrm{ml}$ of ground inoculum was placed next to each root as described by Ruppel et al. (41). For a control, no inoculum was added to the soil. The plant type-isolate combinations, as described above, were randomly assigned to each of six blocks within the greenhouse. Roots were harvested 28 days postinoculation (DPI) and evaluated as described below. The experiment was analyzed as a randomized complete block experiment using PROC MIXED (SAS 9.1). Blocks, the interaction of isolates-blocks, and the interaction of plant types-blocks were assumed to be random effects in the analysis of variance. Dunnett's one-tailed test $(P=0.05)$ was used to identify isolates that caused disease compared with the control.

Temperature and ground-moisture analyses. Sugar beet seed of Beta-1305 were planted into $10-\mathrm{cm}^{2}$ plastic pot filled with Sunshine potting soil mix number 1 (Sun Gro Horticulture, Seba Beach, Canada). Three seeds were planted per pot. Pots were then placed in a greenhouse with an average day time temperature of $24^{\circ} \mathrm{C}$, an average night time temperature of $16^{\circ} \mathrm{C}$, and a $16-\mathrm{h}$ photoperiod. After 17 days, plants were thinned to one plant per pot and were subsequently placed in one of four growth chambers (PGR15, Conviron, Canada), all set to a 16-h photoperiod, a photon flux of $283 \mu \mathrm{E}$, and temperatures as described below. In all experiments, pots were placed in growth chambers at least 
$36 \mathrm{~h}$ before pathogen inoculation to allow soil to adjust to temperatures in the growth chamber and were watered using water stored in each growth chamber to reduce fluctuations in soil temperature. Growth chambers were adjusted to the desired dayand-night temperature regime based on temperatures obtained every 15 min from WatchDog Data Loggers (Spectrum Technologies) that were placed in each growth chamber near the soil level. Growing degree days (GDDs) were calculated in each growth chamber with SpecWare 9 Basic software (Spectrum Technologies) using temperatures collected from Data Loggers and a base temperature of $1.1^{\circ} \mathrm{C}$ (8). Soil temperature was measured with a WatchDog Data Logger outfitted with soil temperature probe.

Experiment I. Growth chambers were set for day and night temperatures of 10 and 4.4, 15.6 and 10, 21.1 and 15.6, or 26.7 and $21.1^{\circ} \mathrm{C}$, corresponding to an average GDD calculation of 7 , 11, 16, and 22 GDDs/day, respectively. Pots were watered on an as-needed basis according to visual assessments. The experimental design was a split-plot with the four temperature regimes as the main plots and the AGs ( $R$. solani AG-2-2 IIIB, AG-2-2 IV, and mock inoculated) as subplots. Replication was conducted over time. Temperature and AG were assumed to be fixed effects in the analysis of variance (PROC MIXED; SAS 9.1). For each of two replicates, plants were subjected to all four temperatures simultaneously in four growth chambers. The temperature treatments were randomly assigned to growth chambers for each replicate. Twelve plants were inoculated with each AG for each temperature. Disease was quantified using the root disease index (RDI; see below) at 14 DPI. No disease occurred at 7 GDDs/day; therefore, only temperature treatments of 11, 16, and 22 GDDs/ day were included in the analysis of variance. No disease occurred on any of the mock-inoculated plants; therefore, they were not included in the analysis of variance for this or any of the experiments described in this article.

Experiment II. Because no infection took place in the growth chamber set to $7 \mathrm{GDDs} / \mathrm{day}$, a second experiment was run to determine the minimum temperature for infection. Growth chambers were set for day and night temperatures of 12.2 and 6.7, 13.3 and $7.8,14.4$ and 8.9 , and 15.6 and $10^{\circ} \mathrm{C}$, corresponding to average GDD calculations of 8, 9, 10, and 11 GDDs/day, respectively. Except for different temperature treatments, experiment II was designed and conducted in a manner identical to experiment I. The RDI was carried out at 14 DPI. The RDI for all temperature treatments, except 11 GDDs/day, was zero. Therefore, these data were not subjected to statistical analyses or reported because 11 GDD was included in experiment I.

Experiment III. This experiment was designed and conducted in a manner identical to experiment I except that the independent variable, leaf disease index (LDI; see below), was measured 6, 10, and 14 DPI. Growth chambers were set for average GDD calculations of 10, 11, 16, and 22 GDDs/day. Because no infection took place at 10 GDDs/day, only 11, 16, and 22 GDDs/day were included in the analysis. The experiment was analyzed as a split plot with the four temperature regimes serving as levels of the main plot factor and AGs (AG-2-2 IIIB and AG-2-2 IV) as the subplot factor. Replication was conducted over time using PROC MIXED (SAS 9.1), with the two replicates and the temperaturereplicate interaction considered random effects and DPI a repeated measure (30).

Soil moisture. For soil moisture evaluation experiments, pots were prepared identically using the same volume of dried soil. Seed of Beta-1305 were planted three per pot and thinned to one plant after seedling establishment. Plants were grown in the greenhouse and all plants were given identical volumes of water. At 14 days after planting, water was withheld from all plants for 3 days, after which plants were moved to two growth chambers set for day and night temperatures of 26.7 and $21.1^{\circ} \mathrm{C}$ (22 GDDs/day, the most conducive regime determined above) (see Results) and were watered to $25,50,75$, or $100 \%$ moisture-holding capacity (MHC). MHC was calculated as described by Dorrance et al. (9). The average difference between soil dry weight (120 g) and wet weight $(584 \mathrm{~g})$ was $464 \mathrm{~g}$. Therefore, soil moisture treatments set at $25,50,75$, and $100 \%$ of MHC were the equivalent of total pot weight of 236, 352, 468, and 584 g, respectively. After 3 days, plants were inoculated with $R$. solani AG-2-2 IIIB and AG-2-2 IV by placing one $R$. solani-infected barley seed $\approx 1.5 \mathrm{~cm}$ below the soil surface and $\approx 1.5 \mathrm{~cm}$ away from the sugar beet hypocotyl. Mock inoculations were the same as above except that autoclaved barley seed were used instead of inoculated seed. Plants were maintained at their respective MHC by weighing each pot and adding water up to their MHC weight every 2 days. Plants were subjected to all MHCs simultaneously in two growth chambers in each of two runs. Plants were arranged in a randomized complete block design with three blocks for each $\operatorname{MHC}(25,50,75$, and $100 \%$ ) and AG (AG-2-2 IIIB and AG-2-2 IV) combination in each growth chamber. The experimental unit for the analysis of variance was the average disease index of two plants for each MHC-AG combination within a block. The experiment was analyzed as a series of randomized complete block experiments combined over four growth chambers (two runs with two chambers per run) using PROC GLM (SAS 9.1; SAS Institute Inc.). AG and MHC were assumed to be fixed effects.

Fungal growth rate tests. Because $R$. solani AG-2-2 IIIB was shown to be more aggressive than AG-2-2 IV (see Results), we were interested in testing whether AG-2-2 IIIB had faster saprophytic growth rate than AG-2-2 IV. To investigate this, isolates of $R$. solani AG-2-2 IIIB and AG-2-2 IV were tested for their ability to cause disease at varying distances from the plant hypocotyl. Plants were inoculated with $R$. solani AG-2-2 IIIB or AG-2-2 IV 17 days after planting by placing a single infested barley kernel 1,4 , or $8 \mathrm{~cm}$ from the plant hypocotyl at $1.5 \mathrm{~cm}$ below the soil surface. Nine days after infection, plants were evaluated for disease as described below. Plants were arranged in a randomized complete block design with four blocks each containing the six distance-AG (R. solani AG-2-2 IIIB or AG-2-2 IV inoculated) combinations in each of two runs. The experimental unit for the analysis of variance was the average disease index of four plants for each treatment combination within a block. The experiment was analyzed as a series of randomized complete block experiments combined over runs (PROC GLM; SAS 9.1). AG and distance from the hypocotyl were assumed to be fixed effects.

Fungicide trials. To evaluate the efficacy of several fungicides for controlling Rhizoctonia root and crown rot caused by AG-2-2 IIIB and AG-2-2 IV, sugar beet seed of Beta-1305 were planted into $10-\mathrm{cm}^{2}$ plastic pots filled with Sunshine potting soil mix number 1 . Three seeds were planted per pot. Pots were then placed in a greenhouse with an average day temperature of $24^{\circ} \mathrm{C}$, an average night temperature of $16^{\circ} \mathrm{C}$, and a 16 -h photoperiod. Each pot was thinned to one plant per pot after seedling establishment. At $\approx 17$ days after planting, plants were inoculated with $R$. solani AG-2-2 IIIB or AG-2-2 IV as described above. Fungicide treatments were administered to 16 plants of each inoculation group with a chain-driven chamber sprayer within $2 \mathrm{~h}$ of inoculation. The sprayer was calibrated to deliver 122 liters $\mathrm{ha}^{-1}$ by compressed air at $276 \mathrm{kPa}$ through a TeeJet 4001 even fan nozzle (Spraying Systems Co., Wheaton, IL). Fungicide treatments included Quadris 2.08 F (azoxystrobin; Syngenta) at 0.672 liter ha ${ }^{-1}$, Proline 480 SC (prothioconazole; Bayer Crop Science) at 0.416 liter $\mathrm{ha}^{-1}$ supplemented with $0.125 \%$ (vol/vol) nonionic surfactant, Headline 2.09 EC (pyraclostrobin; BASF) at 0.658 liter $\mathrm{ha}^{-1}$, Inspire XT 2.08 EC (difenoconazole/propiconazole; Syngenta) at 0.511 liter $\mathrm{ha}^{-1}$, Moncut 70-DF (flutolanil; Nichino America) at $1.233 \mathrm{~kg} \mathrm{ha}^{-1}$, Endorse $11.3 \mathrm{WP}$ (polyoxin D; Arysta Life Science North America) at $2.018 \mathrm{~kg} \mathrm{ha}^{-1}$, and a water control. All plants were allowed to dry $(\approx 30 \mathrm{~min})$ prior to being 
placed in growth chambers that were set for day and night temperatures of 26.7 and $21.1^{\circ} \mathrm{C}$ (22 GDDs/day). Eight plants of each fungicide-ISG combination were placed in each of two growth chambers. Growth chambers were monitored for temperature consistency with Data Loggers (Spectrum Technologies). Each plant was maintained at $100 \%$ MHC during the 2-week disease development period. The RDI was carried out at 12 DPI. The experiment design was a two (ISGs)-by-seven (fungicide or control treatments) factorial with three replicates (blocks), with replication being conducted over time. The average RDI of 16 plants per replicate was the experimental unit used in the analysis of variance (PROC GLM; SAS 9.1). AGs and fungicides were assumed to be fixed effects.

Disease evaluation. For the analysis of pathogenicity of R. solani AGs and subgroups to 10-week-old sugar beet plants, the RDI was calculated 28 DPI. For temperature evaluation experiments, disease progress was evaluated using either the LDI with a scale of 0 to 8 where each wilted leaf (from 0 up to 8 wilted leaves) was counted per plant at 6,10 , and 14 DPI, or the RDI with 1 to 7 scale where $1=$ superficial damage to the skin, 2 to $6=$ up to $5,25,5075,100 \%$ rot of the skin, respectively, and $7=$ $100 \%$ rot of skin and root (48) at 14 DPI. For soil moisture, distance, and fungicide experiments, roots were evaluated using the RDI at 12 DPI.

\section{RESULTS}

PCR assays. To test the ability of PCR to reliably discriminate between ISGs AG-2-2 IIIB and AG-2-2 IV, a variety of primers were tested in PCRs with gradients of both annealing temperature and final $\mathrm{MgCl}_{2}$ concentration. A PCR product of $\approx 475$ bp was obtained exclusively from AG-2-2 IIIB DNA when using the AG2-2 IIIB-specific primer set, a final $\mathrm{MgCl}_{2}$ concentration of $1.5 \mathrm{mM}$, and an annealing temperature of $58^{\circ} \mathrm{C}$ (not shown). Likewise, a PCR product of similar size was obtained exclusively from AG-2-2 IV DNA when using the AG-2-2 IV-specific primer set (6), a final $\mathrm{MgCl}_{2}$ concentration of $2.5 \mathrm{mM}$, and an annealing temperature of $66.5^{\circ} \mathrm{C}$ (not shown). In addition, the ISG of AG-22 IIIB isolates were corroborated by growth on PDA at $35^{\circ} \mathrm{C}$, whereas AG-2-2 IV isolates were unable to grow at this temperature.

Pathogenicity of $\boldsymbol{R}$. solani AGs on sugar beet. A collection of $R$. solani isolates representing $15 R$. solani AGs and ISGs were used to assess pathogenicity of susceptible and resistant sugar beet seedlings and 10-week-old plants. Because the plant type main effect was not significant and there were no plant-isolate interactions, only the main effect of isolate across plant type was summarized (Fig. 1A). Control emergence was $66.5 \%$ in seedling assays. Seedling emergence from soil inoculated with AG-1, AG1 IB, AG-1 IC, AG-2-2 IIIB, AG-2-2 IV, and AG-4 was less that emergence from the sterile barley control $(P=0.05)$ (Fig. 1A). Seedlings had the lowest emergence rate when grown in AG-2-2 IIIB-infested soil (Fig. 1A).

The isolates above were also used to assess pathogenicity of 10 -week-old plants. The plant type, isolate, and isolate-plant-type interaction were all significant; therefore, the data are presented separately for susceptible and resistant plants (Fig. 1B). The RDI of the susceptible cv. Monohikari was greater than the RDI of the noninoculated susceptible control $(P=0.05)$ when grown in soil containing AG-2-2 IIIB and AG-2-2 IV (Fig. 1B). The R. solaniresistant cv. FC708 CMS had a higher RDI than the noninoculated resistant control $(P=0.05)$ only when exposed to AG2-2 IIIB (Fig. 1B). The average RDI of the susceptible cv. Monohikari was 6.1 and 4.1 when inoculated with AG-2-2 IIIB and AG-2-2 IV, respectively, suggesting that these ISGs represent the most aggressive $R$. solani AGs and ISGs on sugar beet (Fig. 1B).

Identification of temperatures governing infection of $\boldsymbol{R}$. solani AG-2-2 IIIB and 2-2 IV. Because pathogenicity studies indicated that isolates of AG-2-2 IIIB and AG-2-2 IV were consistently the most virulent on sugar beet, these ISGs were used to determine environmental parameters most conducive to infection. The RDI was calculated on all plants at 14 DPI in temperature evaluation experiments I and II and no disease symptoms were found on any plants grown at $\leq 10$ GDDs. Therefore, statistical analysis was only carried out on the data obtained from plants growing at 11,16 , and 22 GDDs/day in experiment I. Both the ISG and temperature main effects and the interaction of ISGtemperature were significant (Table 1). In growth chambers set for $\geq 11$ GDDs, RDI values correlated positively with increasing temperature (Fig. 2A). Plants inoculated with either ISG grown in the 22 GDD growth chamber had higher RDS values than those held at 16 GDDs. Plants inoculated with AG-2-2 IIIB had higher RDI values than those inoculated with AG-2-2 IV in both 16 and 22 GDD growth chambers. Soil temperature of plants grown in the 11 GDD growth chamber representing the lowest temperature regime in which infection occurred oscillated between $15.0^{\circ} \mathrm{C}$ (day) and $9.8^{\circ} \mathrm{C}$ (night). In all experiments, no disease symptoms were seen on any mock-inoculated plant.

To further clarify the role of temperature on disease development, the LDI was used as a measure of disease severity at three time points after inoculation in temperature evaluation experiment III. Plants inoculated with either AG-2-2 IIIB or AG-2-2 IV showed foliar symptoms by 14 DPI when grown at 11 GDDs (Fig. 3 ). Foliar symptoms occurred earlier and were more pronounced in inoculated plants grown at higher temperatures. For example, plants inoculated with either ISG showed significant disease symptoms by 10 DPI when grown at 16 GDDs and as early as 6 DPI on inoculated plants grown at 22 GDDs (Fig. 3). In growth chambers at both 16 and 22 GDDs, there was a tendency for plants inoculated with AG-2-2 IIIB to have higher LDI ratings than plants inoculated with AG-2-2 IV (Fig. 3).

Identification of soil moisture parameters influencing infection of $R$. solani AG-2-2 IIIB and 2-2 IV. ISG and MHC main effects were significant; however, the interaction between the two was not significant (Table 2). Plants inoculated with either AG-22 IIIB or AG-2-2 IV showed a positive correlation between RDI and the amount of water applied up to $75 \% \mathrm{MHC}$ at $12 \mathrm{DPI}$ (Fig. 2B). Plants maintained at $100 \% \mathrm{MHC}$ had root disease index levels similar to plants at $75 \% \mathrm{MHC}$ (Fig. 2B). Plants inoculated with AG-2-2 IIIB had higher RDI values than those inoculated with AG-2-2 IV in all MHC treatments (Fig. 2B).

Growth rates of AG-2-2 IIIB and AG-2-2 IV. Both the ISG and distance main effects and the interaction of ISG-distance were significant (Table 2). Disease severity was inversely correlated with inoculum distance (Fig. 4). The RDI was similar for plants inoculated with either ISG $1 \mathrm{~cm}$ from the hypocotyl. However, plants inoculated with AG-2-2 IIIB had a significantly higher RDI than those inoculated with AG-2-2 IV at $8 \mathrm{~cm}$ (Fig. 4).

Fungicide trials. Using conditions identified as optimal for $R$. solani disease development, we tested the efficacy of several fungicides to control Rhizoctonia root and crown rot. ISGs and fungicides main effects were significant; however, the interaction of ISG-fungicide was not significant (Table 2). Plants with flutolanil, polyoxin D, and azoxystrobin applications had the lowest RDI values (Fig. 5). Leaves of plants treated with difenoconazole/propiconazole exhibited a dark-green color and were slightly stunted relative to mock-inoculated controls (not shown).

\section{DISCUSSION}

Virulence levels and host range are important characteristics of $R$. solani isolates and provide fundamental information for disease management. Earlier reports had indicated that AG-2-2 IV was the primary causal agent for Rhizoctonia root and crown rot in sugar beet $(11,35,49)$. Recent studies have shown that changes 
in crop rotation strategies in the Red River Valley may be responsible for increasing the prevalence of AGs pathogenic to sugar beet (3). Because Rhizoctonia root and crown rot has become an increasing threat to sugar beet production in this region and, to our knowledge, no previous studies have assessed which AGs and ISGs are pathogenic to sugar beet, we sought to perform a comprehensive catalog of AGs and ISGs that are able to infect sugar beet seedlings and 10-week-old plants. Although

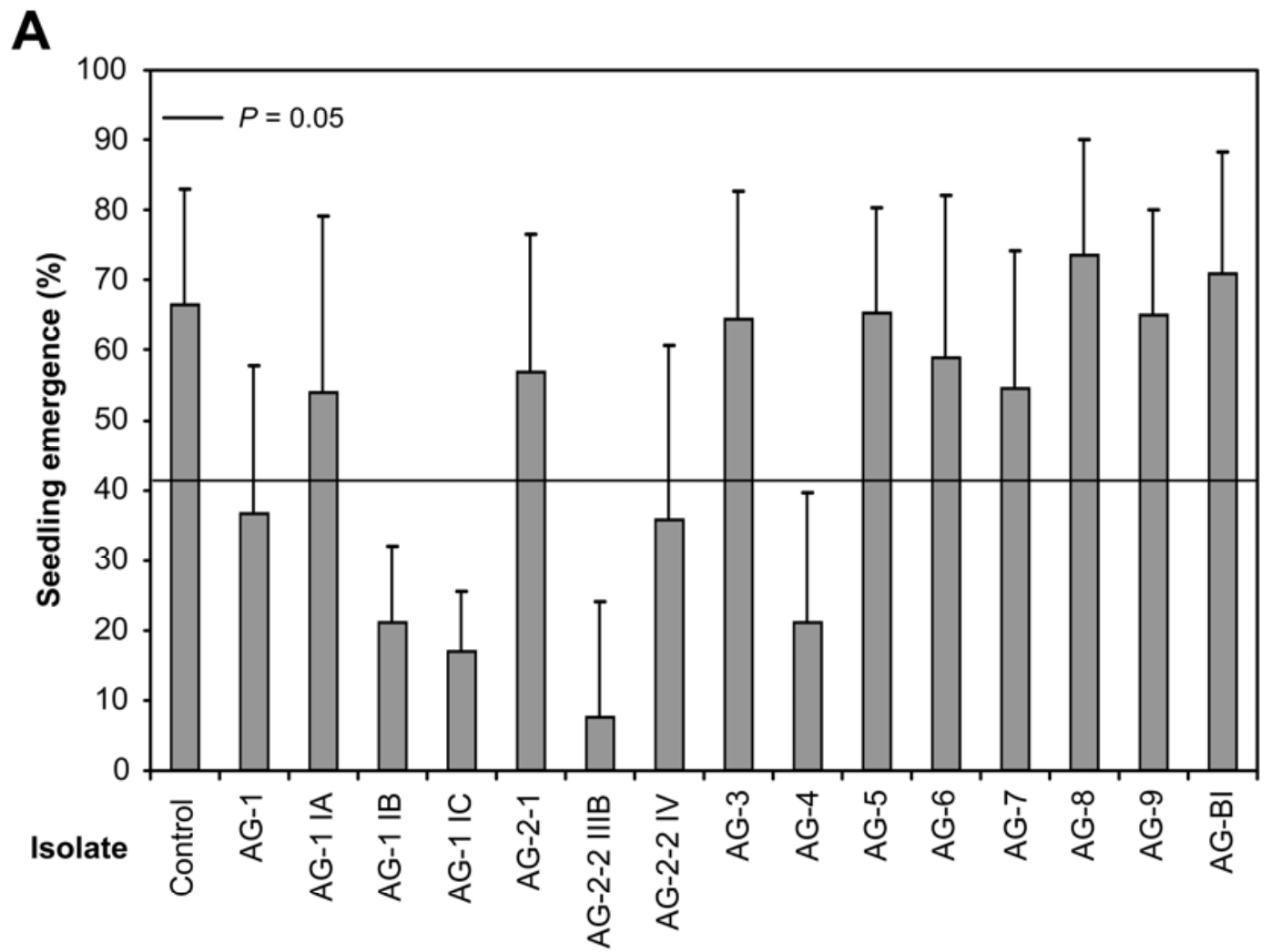

B

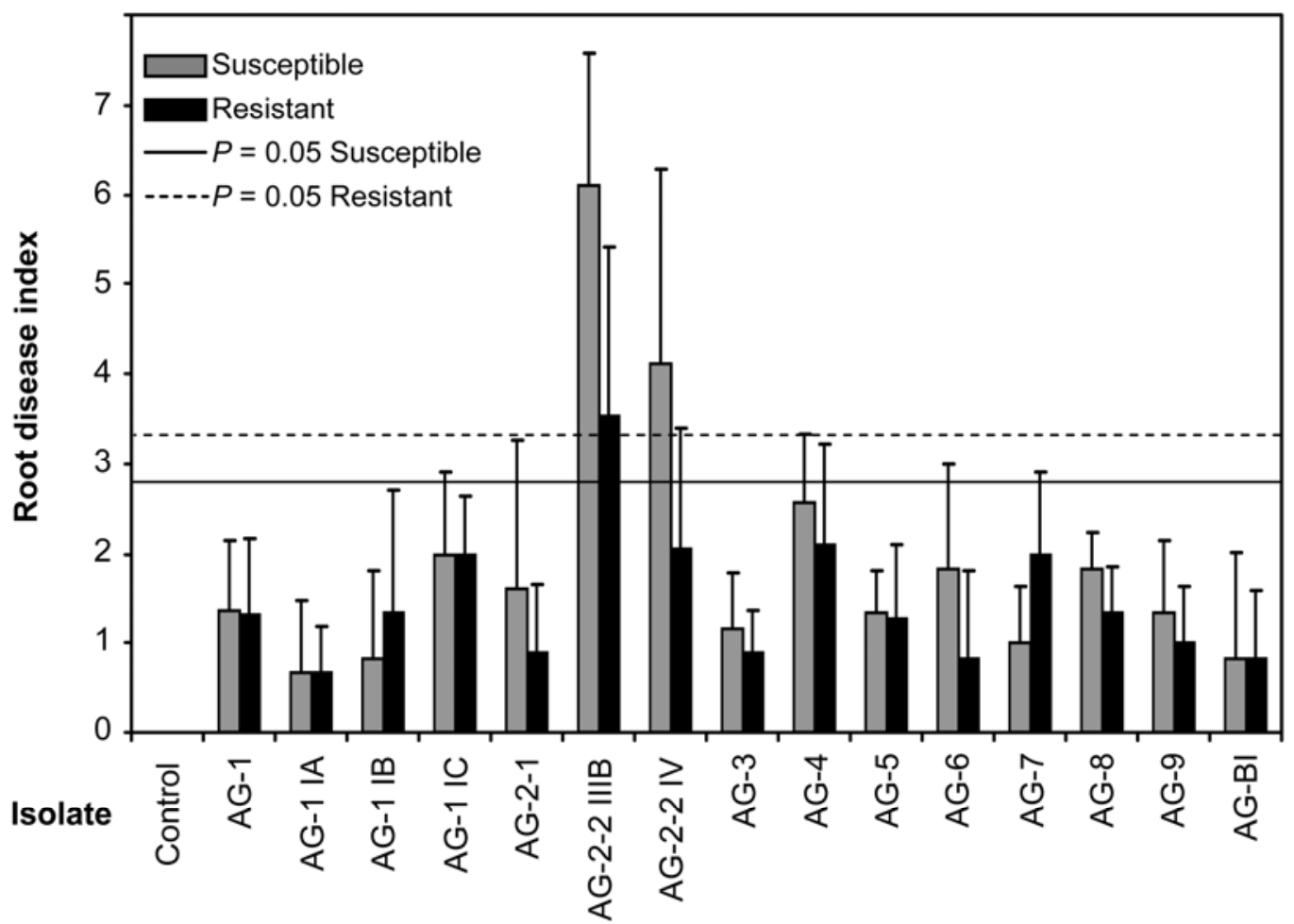

Fig. 1. Disease development in the Rhizoctonia solani-susceptible Monohikari and $R$. solani-resistant FC708 CMS sugar beet hybrids. A, Seedling emergence 21 days after planting into soil infected with $R$. solani anastomosis groups (AGs) and intraspecific groups (ISGs). All values below the horizontal line (41\%) differ from the noninoculated control based upon Dunnett's one-tailed test $(P=0.05)$. Error bars represent the standard deviation of the mean. B, Root disease ratings of plants inoculated at 10 weeks after planting with $R$. solani AGs and ISGs. All values above the horizontal line for susceptible (2.81) and resistant (3.31) hybrids differ from the corresponding noninoculated control based upon Dunnett's one-tailed test $(P=0.05)$. Error bars represent the standard deviation of the mean. 
many of the isolates in our study were able to affect seedling emergence to some extent, isolates of AG-1, AG-1 IB, AG-1 IC, AG-2-2 IIIB, AG-2-2 IV, and AG-4 were the most virulent and resulted in the most significant decrease in sugar beet seedling emergence. In previous studies, these AGs and ISGs have been shown to be pathogenic on crops presently grown in the Red River Valley. For example, AG-1 IB, AG-1 IC, AG-2-2 IIIB, or AG-4 have previously been shown to cause disease in soybean, common bean, maize, potato, and various oilseed crops $(6,14$, 23,34-36,49,55,56). Future studies directed toward assessing the frequency and distribution of these AGs and ISGs in the Red River Valley will need to be carried out to assess whether recent changes in crop rotation are affecting their prevalence in the region.

As plants mature, they are likely to become less susceptible to some AGs. The results of this study substantiate this claim because only AG-2-2 IIIB and AG-2-2 IV caused significant disease in 10-week-old plants. Similar results were obtained by Windels and Nabben, who isolated three AGs $91 \%$ of the time from seedlings grown in the Red River Valley but isolated AG-2-2 $96 \%$ of the time from plants $>8$ weeks old (55). Interestingly, although the $R$. solani-resistant sugar beet cv. FC708 CMS was typically more resistant than the susceptible cv. Monohikari in the 10 -week-old plants, there was no resistance in seedling assays (Fig. 1). Germplasm with resistance to $R$. solani does not express resistance until after the seedling stage (12).

Although there have been documented reports of AG-2-2 on sugar beet, many have not differentiated between AG-2-2 IIIB and AG-2-2 IV (49). Because host range and hyphal anastomosis cannot be used to distinguish AG-2-2 IIIB and AG-2-2 IV (6,11, 35 ), several studies have focused on in vitro or molecular techniques to differentiate $R$. solani AG-2-2 ISGs based on differential growth at elevated temperatures $(3,11)$, fatty acid composition (22), or isozyme and DNA restriction analyses (31,32). More recently, sequence polymorphism in the internal transcribed spacer (ITS) region has been exploited to differentiate these ISGs $(6,43)$. Although the previously published primer pair P22-IV was useful to distinguish AG-2-2 IV isolates in our study, we were unable to reliably differentiate AG-2-2 IIIB from AG-2-2 IV using primer pair P22-IIIB (6), perhaps due to high level of heterogeneity in AG-2 (14). Other laboratories have reported similar problems with the primers (L. Panella, unpublished data; C. Windels, personal communication). Therefore, we developed the primer pair MDB-034 and MDB-035 and PCR conditions that reliably differentiated the AG-2-2 IIIB isolates from AG-2-2 IV isolates used in this study. However, ITS sequence differences can only be expected to differentiate between all AG-2-2 IIIB and AG-2-2 IV isolates when there is no gene flow (or recombination) between these ISGs. We have no conclusive evidence that this is so and, therefore, ISG classification was corroborated by differential growth at $35^{\circ} \mathrm{C}$ as described earlier $(3,11,48)$.

TABLE 1. Analysis of variance for temperature experiments with Rhizoctonia solani AG-2-2 IIIB and AG-2-2 IV

\begin{tabular}{llrr}
\hline Source $^{\mathrm{a}}$ & df & $F$ & $P$ \\
\hline Experiment I & & & \\
$\quad$ Temperature & 2 & 867.4 & 0.0012 \\
Isolate & 1 & 696.2 & 0.0001 \\
$\quad$ Isolate $\times$ temperature & 2 & 348.2 & 0.0003 \\
Experiment III & & & \\
Temperature & 2 & 380.6 & 0.0026 \\
Isolate & 1 & 192.0 & $<0.0001$ \\
DPI & 2 & 430.3 & $<0.0001$ \\
Isolate $\times$ temperature & 2 & 95.5 & $<0.0001$ \\
Isolate $\times$ DPI & 2 & 9.1 & $<0.0001$ \\
Temperature $\times$ DPI & 4 & 79.8 & $<0.0001$ \\
Temperature $\times$ isolate $\times$ DPI & 4 & 7.0 & $<0.0001$ \\
\hline
\end{tabular}

${ }^{\text {a }}$ DPI $=$ days postinoculation.
In general, Rhizoctonia root and crown rot is known to be favored by "warm and wet" conditions $(28,42)$ but the effects of either temperature or soil moisture on sugar beet infection have not been quantified. Because we were primarily interested in spring temperatures that were relevant to the Red River Valley when the first fungicide applications aimed at $R$. solani traditionally occur, we evaluated temperature regimes from 7 to 22 GDDs/ day. GDD is the most common temperature index to estimate plant development and is often used to establish thresholds for plant disease $(19,46)$. Furthermore, GDDs are calculated each day for the Red River Valley growing region by the North Dakota Agricultural Weather Network (http://ndawn.ndsu.nodak.edu/), allowing growers to access GDD information. Neither ISG was able to cause disease at $\leq 10$ GDDs/day but both were able to cause disease at 11 GDDs/day. However, soil temperature is known to increase in a direct relationship to air temperature, with the effect diminishing as soil depth increases (28). Because soil temperature oscillated between $15.0^{\circ} \mathrm{C}$ (day) and $9.8^{\circ} \mathrm{C}$ (night) in the 11 GDDs/day growth chamber, soil temperature measurements may also be a useful way of predicting when $R$. solani infection can occur. Future research directed toward the validation of GDD requirements for infection under field conditions will need to be carried out.

The relationship of temperature to $R$. solani disease development has been measured in a wide variety of crops $(7,9,13$, $18,24,47,51)$. In this study, disease severity was positively cor-

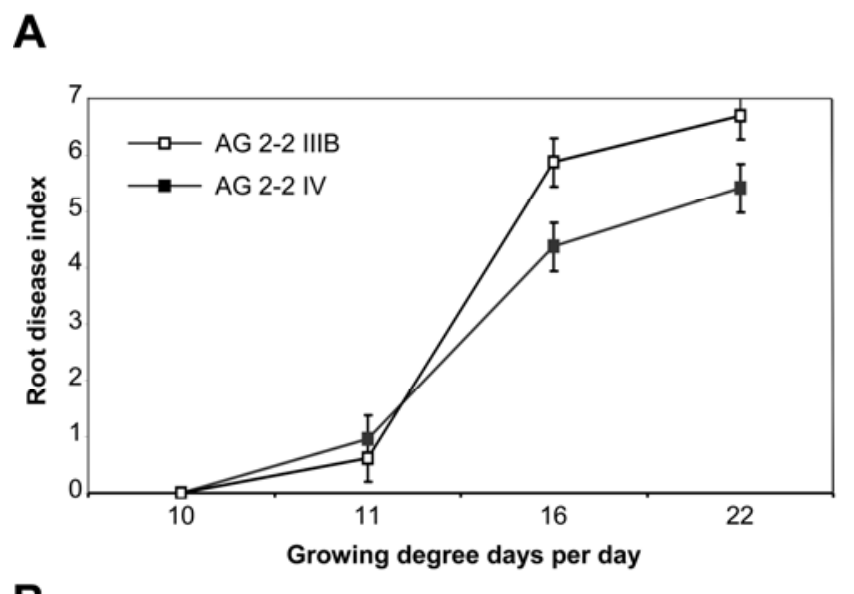

B

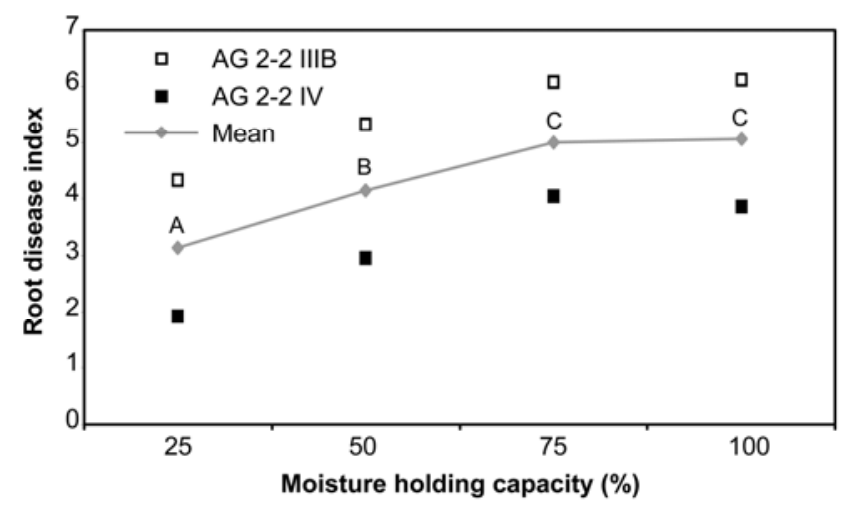

Fig. 2. Effect of temperature and moisture on disease progress of Rhizoctonia solani anastomosis group (AG)-2-2 IIIB and AG-2-2 IV. A, Root disease ratings of plants inoculated with $R$. solani AG-2-2 IIIB and AG-2-2 IV at 10, 11,16 , and 22 growing degree days per day. Error bars represent the $95 \%$ confidence limits of the mean. B, Root disease ratings of plants inoculated with $R$. solani AG-2-2 IIIB and AG-2-2 IV at 25, 50, 75, and 100\% moistureholding capacity. The line represents the mean root disease index value for both intraspecific groups. Points on the line designated by a common letter are not significantly different according to Fishers protected least significant difference $(P=0.05)$. 
related with increasing temperature. Isolates of AG-2-2 IIIB are known to grow well at $35^{\circ} \mathrm{C}$ in vitro (48), perhaps suggesting that disease from AG-2-2 IIIB may progress more quickly at higher temperatures. However, Dorrance et al. (9) found that temperatures of 20 to $32^{\circ} \mathrm{C}$ were not a critical factor in the infection process of AG-2-2 IIIB on soybean. In contrast, it was suggested that AG-2-2 IIIB was less aggressive than AG-4 on soybean grown in the Red River Valley due to the cool temperatures that typically occur in this region (34).

The relationship of ground moisture to disease development has been speculated to be an important component of Rhizoctonia root and crown rot disease management (28) but reports quantifying the effect are lacking. Soil moisture affected disease severity in this study. Although plants at $25 \%$ MHC had the lowest disease severity, it is important to note that soil moisture levels in these pots were just enough to keep plants from wilting. Therefore, very low soil moisture is adequate for disease to occur but is less conducive for disease development. Brantner and Windels (3) found that AG-2-2 IIIB was predominant in the sugar-beet-growing area of southern Minnesota whereas AG-2-2 IV was predominant in the Red River Valley, perhaps reflecting the historical pattern of crop rotation in each location. Small grain crops have traditionally been a favored rotational crop in the Red River Valley but a recent increase in production of soybean and corn may promote buildup of AG-2-2 IIIB (3). Interestingly, southern Minnesota has grown corn and soybean in rotation with sugar beet for decades without severe outbreaks of Rhizoctonia root and crown rot. However, this may possibly be explained by early sugar beet planting schedules in southern Minnesota which are known to lower disease severity (10). In addition, because the results of our study suggest that ground moisture plays a role in disease development, southern Minnesota drainage conditions may provide environments less conducive for disease development than the Red River Valley.
Differential growth rates of $R$. solani AGs have been reported and were suggested to impact disease severity (29). We performed an assay to see whether AG-2-2 IIIB could initiate disease faster that AG-2-2 IV by placing inoculum at varying distances from the

TABLE 2. Analysis of variance for soil moisture, growth rate, and fungicide experiments with Rhizoctonia solani AG-2-2 IIIB and AG-2-2 IV

\begin{tabular}{lrrrc}
\hline Source & df & Mean squares & \multicolumn{1}{c}{$F$} & $P$ \\
\hline Soil moisture & & & & \\
$\quad$ Runs & 3 & 0.7152 & 0.8 & 0.5230 \\
Blocks (runs) & 8 & 0.8828 & $\ldots$ & $\ldots$ \\
Isolate & 1 & 123.7604 & 245.2 & $<0.0001$ \\
MHC & 3 & 19.7708 & 39.2 & $<0.0001$ \\
Isolate $\times$ MHC & 3 & 0.1701 & 0.3 & 0.7986 \\
Run $\times$ isolate & 3 & 0.6979 & 1.4 & 0.2576 \\
Run $\times$ MHC & 9 & 0.9398 & 1.9 & 0.0771 \\
Run $\times$ isolate $\times$ MHC & 9 & 1.0799 & 2.1 & 0.0409 \\
$\quad$ Error & 56 & 0.5048 & $\ldots$ & $\ldots$ \\
Growth rate & & & & \\
$\quad$ Runs & 1 & 1.5950 & 2.1 & 0.198 \\
Blocks (runs) & 6 & 0.7617 & $\ldots$ & $\ldots$ \\
Isolate & 1 & 7.3242 & 17.1 & $<0.0003$ \\
Distance & 2 & 62.6302 & 146.6 & $<0.0001$ \\
Isolate $\times$ distance & 2 & 3.8593 & 9.0 & 0.0009 \\
Run $\times$ isolate & 1 & 0.3255 & 0.1 & 0.7844 \\
Run $\times$ distance & 2 & 0.2083 & 0.1 & 0.9525 \\
Run $\times$ isolate $\times$ distance & 2 & 0.0833 & 0.2 & 0.8239 \\
$\quad$ Error & 30 & 0.4273 & $\ldots$ & $\ldots$ \\
Fungicide & & & & \\
Blocks (replications) & 2 & 79.6915 & $\ldots$ & $\ldots$ \\
Isolate & 1 & 6.0004 & 11.1 & 0.0026 \\
Fungicide & 6 & 6.2985 & 11.6 & $<0.0001$ \\
Isolate $\times$ fungicide & 6 & 0.4327 & 0.8 & 0.5805 \\
Error & 26 & 0.5425 & $\ldots$ & $\ldots$ \\
\hline MHC & &
\end{tabular}

${ }^{\mathrm{a}} \mathrm{MHC}=$ moisture-holding capacity and distance $=$ inoculum distance $(\mathrm{cm})$ from hypocotyl.

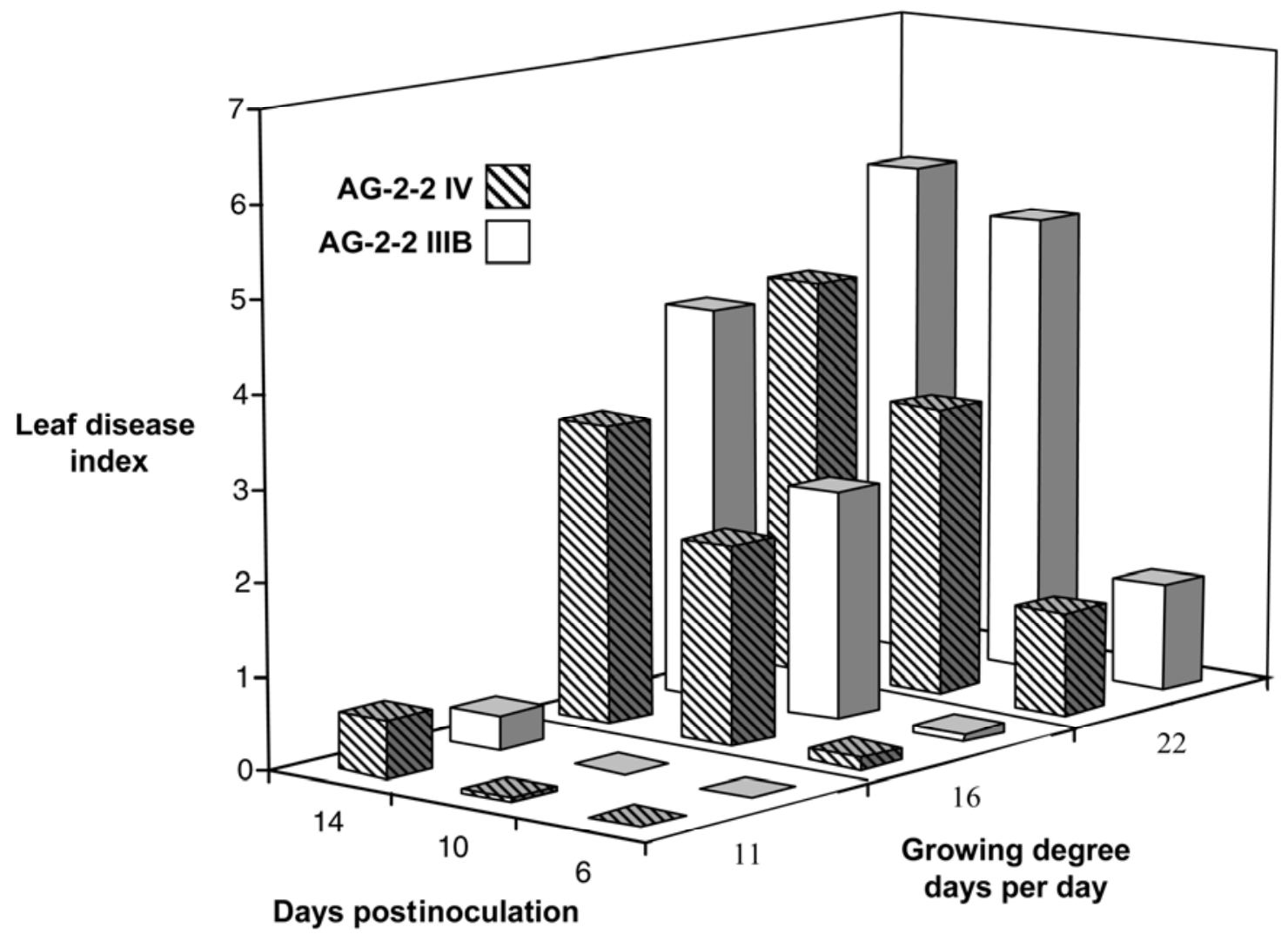

Fig. 3. Evaluation of disease progress using the leaf disease index (LDI). Disease progress of Rhizoctonia solani anastomosis group (AG)-2-2 IIIB and AG-2-2 IV estimated with the LDI at 6,10 , and 14 days postinoculation at 11,16 , and 22 growing degree days per day. Standard error of the isolate $\times$ temperature $\times$ DPI LDI means is 0.1695 . 


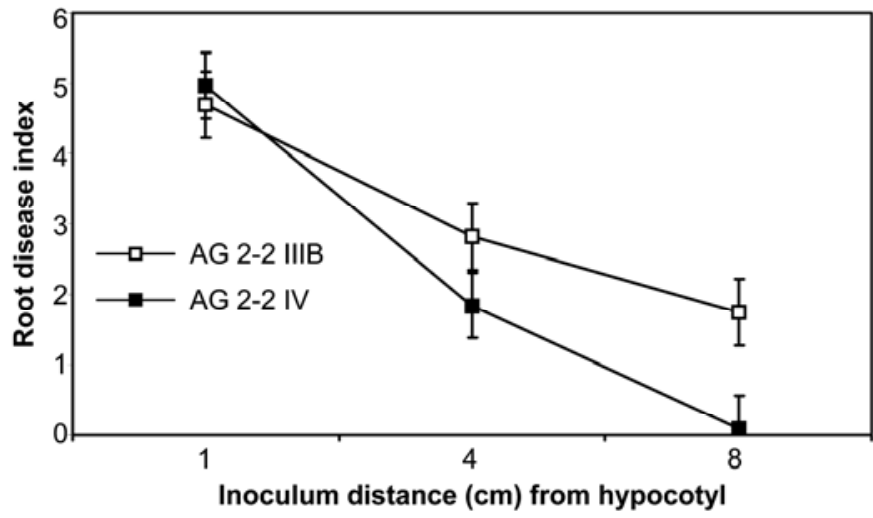

Fig. 4. Effect of inoculum distance on disease progress of Rhizoctonia solani anastomosis group (AG)-2-2 IIIB and AG-2-2 IV. Root disease ratings of plants inoculated with $R$. solani AG-2-2 IIIB and AG-2-2 IV at 1, 4, and $8 \mathrm{~cm}$ from the sugar beet hypocotyl. Error bars represent the $95 \%$ confidence limits of the mean.

sugar beet hypocotyl. We found that disease severity diminished as inoculum was placed farther from the hypocotyl for both ISGs. However, AG-2-2 IIIB was consistently able to cause disease symptoms from $8 \mathrm{~cm}$ away from the plant hypocotyl during the evaluation period, whereas AG-2-2 IV was unable to do so during the same time period. This suggests that AG-2-2 IIIB was better able to grow saprophytically through the soil than AG-2-2 IV. However, AG-2-2 IIIB typically grows faster than AG-2-2 IV on PDA plates (personal observations), suggesting that relative growth rate is not necessarily dependent on substrate. Although every effort was made to ensure that inoculum of AG-2-2 IIIB and AG-2-2 IV were produced under identical conditions, we cannot rule out that AG-2-2 IIIB grew faster than AG-2-2 IV on the barley kernels during inoculum preparation and, therefore, more inoculum was present in AG-2-2 IIIB-inoculated plants. However, CFU were used in seedling assays to ensure that potential differential growth rates were not a factor. In these assays, AG-2-2 IIIB was still the most aggressive ISG.

In the absence of $R$. solani, cultivars resistant to Rhizoctonia root and crown rot do not yield as well as susceptible cultivars (38). Until high-yielding $R$. solani-resistant germplasm is available, fungicides that suppress $R$. solani disease development will be an important tool for Rhizoctonia root and crown rot management. In this study, we tested the efficacy of six fungicides under controlled climate conditions we identified as most favorable for fungal growth. We found that plants treated with difenoconazole/propiconazole, a fungicide not typically used to control $R$. solani (25), had disease levels similar to the water control. However, the fungicides polyoxin-d, flutolanil, and azoxystrobin were able to lower disease severity by nearly half relative to the water control. Polyoxin-d and flutolanil are used to control $R$. solani in several pathosystems $(5,16,33,39)$ but little is known about the efficacy of these fungicides to control Rhizoctonia root and crown rot. Sugar beet growers have traditionally relied on azoxystrobin to manage disease, suggesting that the conditions used to assess fungicide efficacy in this study are suitable for identification of compounds that have known merit in the field.

$R$. solani continues to be a destructive pathogen on sugar beet. An understanding of the effect that environmental factors have on infection is necessary to develop management strategies, especially with regards to optimizing fungicide application. These results suggest that $R$. solani AG-2-2 IIIB and AG-2-2 IV infection is influenced by moisture and temperature. Because $R$. solani AG-22 IIIB and AG-2-2 IV are widespread in the sugar-beet-growing area of the Red River Valley (3), knowledge of the environmental conditions that influence infection may allow growers to better time fungicide applications to manage this important disease.

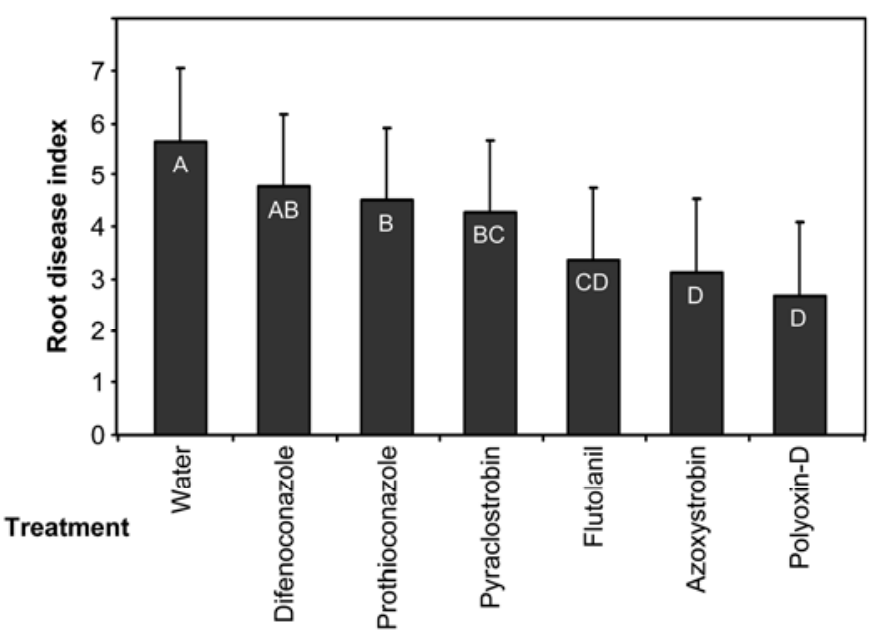

Fig. 5. Root disease ratings of 2.5-week-old plants inoculated with Rhizoctonia solani anastomosis group (AG)-2-2 IIIB and AG-2-2 IV after treatment with Quadris 2.08 F (azoxystrobin; Syngenta) at 0.672 liter ha ${ }^{-1}$, Proline 480 $\mathrm{SC}$ (prothioconazole; Bayer Crop Science) at 0.416 liter $\mathrm{ha}^{-1}$ supplemented with $0.125 \%$ ( $\mathrm{vol} / \mathrm{vol}$ ) nonionic surfactant, Headline 2.09 EC (pyraclostrobin; BASF) at 0.658 liter ha $^{-1}$, Inspire XT $2.08 \mathrm{EC}$ (difenoconazole/propiconazole; Syngenta) at 0.511 liter ha ${ }^{-1}$, Moncut 70-DF (flutolanil; Nichino America) at $1.233 \mathrm{~kg} \mathrm{ha}^{-1}$, Endorse 11.3 WP (polyoxin D; Arysta Life Science North America) at $2.018 \mathrm{~kg} \mathrm{ha}^{-1}$, and a water control. Root disease ratings were at 12 days postinoculation. Bars designated by a common letter are not significantly different according to Fisher's protected least significant difference $(P=0.05)$. Error bars represent the standard error of the mean.

\section{ACKNOWLEDGMENTS}

Mention of trade names or commercial products in this publication is solely for the purpose of providing specific information and does not imply recommendation or endorsement by the USDA. This research was supported by USDA-ARS CRIS projects 5442-22000-042-00D and 540221220-007-00D. We thank C. Windels, University of Minnesota, for providing isolates of R. solani; G. Nielsen, A. Carlson, K. Rudolph, and I. Qandah for technical assistance; S. Markell and R. Goswami (North Dakota State University) for critical review of the manuscript; and D. Garvin and M. S. West (USDA-ARS) for helpful statistics discussions.

\section{LITERATURE CITED}

1. Anderson, N. A. 1982. The genetics and pathology of Rhizoctonia solani. Annu. Rev. Phytopathol. 20:329-347.

2. Bartlett, D. W., Clough, J. M., Godwin, J. R., Hall, A. A., Hamer, M., and Parr-Dobrzanski, B. 2002. The strobilurin fungicides. Pest Manage. Sci. 58:649-662.

3. Brantner, J. R., and Windels, C. E. 2007. Distribution of Rhizoctonia solani AG 2-2 intraspecific groups in the Red River Valley and southern Minnesota. Sugarbeet Res. Ext. Rep. 38:242-246.

4. Buhre, C., Kluth, C., Bürcky, K., Märländer, B., and Varrelmann, M. 2009. Integrated control of root and crown rot in sugar beet: combined effects of cultivar, crop rotation, and soil tillage. Plant Dis. 93:155-161.

5. Butler, E. L., and Tredway, L. P. 2005. Preventative control of brown patch and dollar spot in creeping bentgrass greens, 2004. In: Plant Disease Management Reports. The American Phytopathological Society, St. Paul, MN.

6. Carling, D. E., Kuninaga, S., and Brainard, K. A. 2002. Hyphal anastomosis reactions, rDNA-internal transcribed spacer sequences, and virulence levels among subsets of Rhizoctonia solani anastomosis group-2 (AG-2) and AG-BI. Phytopathology 92:43-50.

7. Carling, D. E., and Leiner, R. H. 1990. Effect of temperature on virulence of Rhizoctonia solani and other Rhizoctonia on potato. Phytopathology 80:930-934.

8. Dale, T. M., and Renner, K. A. 2005. Timing of postemergence micro-rate applications based on growing degree days in sugarbeet. J. Sugar Beet Res. 42:87-101.

9. Dorrance, A. E., Kleinhenz, M. D., McClure, S. A., and Tuttle, N. T. 2003. Temperature, moisture, and seed treatment effects on Rhizoctonia solani root rot of soybean. Plant Dis. 87:533-538.

10. Engelkes, C. A., and Windels, C. E. 1994. Relationship of plant age, 
cultivar, and isolate of Rhizoctonia solani AG-2-2 to sugar beet root and crown rot. Plant Dis. 78:685-689.

11. Engelkes, C. A., and Windels, C. E. 1996. Susceptibility of sugar beet and beans to Rhizoctonia solani AG-2-2 IIIB and AG-2-2 IV. Plant Dis. 80:1413-1417.

12. Gaskill, J. O. 1968. Breeding for Rhizoctonia resistance in sugar beet. J. Am. Soc. Sugar Beet Technol. 15:105-119.

13. Gill, J. S., Sivasithamparam, K., and Smettem, K. R. J. 2001. Effect of soil moisture at different temperatures on Rhizoctonia root rot of wheat seedlings. Plant Soil 231:91-96.

14. Godoy-Lutz, G., Steadman, J. R., Higgins, B., and Powers, K. 2003. Genetic variation among isolates of the web blight pathogen of common bean based on PCR-RFLP of the ITS-rDNA region. Plant Dis. 87:766771.

15. Harveson, R. M., Hanson, L. E., and Hein, G. L., eds. 2009. Compendium of Beet Diseases and Pests. The American Phytopathological Society Press, St. Paul, MN.

16. Hausbeck, M. K., and Harlan, B. R. 2006. Control of Rhizoctonia root rot of zinnia with fungicide drenches, 2005. In: Fungicide and Nematicide Tests. The American Phytopathological Society, St. Paul, MN.

17. Hecker, R. J., and Ruppel, E. G. 1981. Registration of FC 708 and FC 708 CMS sugar beet germplasm. Crop Sci. 21:802.

18. Hide, G. A., and Firmager, J. P. 1989. Effects of soil temperature and moisture on stem canker (Rhizoctonia solani) disease of potatoes. Potato Res. 32:75-80.

19. Holen, C. D., and Dexter, A. 1996. A growing degree day equation for early sugarbeet leaf stages. Sugarbeet Res. Ext. Rep. 27:152-157.

20. Ithurrart, M. E. F., Büttner, G., and Petersen, J. 2004. Rhizoctonia root rot in sugar beet (Beta vulgaris ssp. altissima) - epidemiological aspects in relation to maize (Zea mays) as a host plant. J. Plant Dis. Prot. 111:302312.

21. Jacobsen, B., Kephart, K., Zidack, N., Johnston, M., and Ansley, J. 2004. Effect of fungicide and fungicide application timing on reducing yield loss to Rhizoctonia crown and root rot. Sugarbeet Res. Ext. Rep. 35:224226.

22. Johnk, J. S., and Jones, R. K. 1993. Differentiation of populations of AG2-2 of Rhizoctonia solani by analysis of cellular fatty acids. Phytopathology 83:278-283.

23. Johnk, J. S., and Jones, R. K. 2001. Differentiation of three homogeneous groups of Rhizoctonia solani anastomosis group 4 by analysis of fatty acids. Phytopathology 91:821-830.

24. Júnior, T. P., Rotter, C., and Hau, B. 2007. Effects of soil moisture and sowing depth on the development of bean plants grown in sterile soil infested by Rhizoctonia solani and Trichoderma harzianum. Eur. J. Plant Pathol. 119:193-202.

25. Khan, M. F. R., and Carlson, A. 2009. Efficacy of fungicides for controlling Cercospora leaf spot on sugarbeet. Sugarbeet Res. Ext. Rep. 39:216-219.

26. Khan, M. F. R., Nelson, R., Bradley, C. A., and Khan, J. 2005. Developing a management strategy for controlling Rhizoctonia root and crown rot in sugarbeet. Sugarbeet Res. Ext. Rep. 36:295-295.

27. Kiewnick, S., Jacobsen, B. J., Braun-Kiewnick, A., Eckhoff, J. L. A., and Bergman, J. W. 2001. Integrated control of Rhizoctonia crown and root rot of sugar beet with fungicides and antagonistic bacteria. Plant Dis. 85:718-722.

28. Kirk, W. W., Wharton, P. S., Schafer, R. L., Tumbalam, P., Poindexter, S., Guza, C., Fogg, R., Schlatter, T., Stewart, J., and Hubbell, L. 2008. Optimizing fungicide timing for the control of Rhizoctonia crown and root rot of sugar beet using soil temperature and plant growth stages. Plant Dis. 92:1091-1098.

29. Kumar, S., Sivasithamparam, K., Gill, J. S., and Sweetingham, M. W. 1999. Temperature and water potential effects on growth and pathogenicity of Rhizoctonia solani AG-11 to lupin. Can. J. Microbiol. 45:389395.

30. Littell, R. C., Stroup, W. W., and Freund, R. J. 2002. SAS for Linear Models. SAS Publishing, Cary, NC.

31. Liu, Z., Nickrent, D. L., and Sinclair, J. B. 1990. Genetic relationships among isolates of Rhizoctonia solani anastomosis group-2 based on isozyme analysis. Can. J. Plant Pathol. 12:376-382.

32. Liu, Z. L., Sinclair, J. B., and Chen, W. 1992. Genetic diversity of Rhizoctonia solani anastomosis group 2. Phytopathology 82:778-787.

33. Motoba, K., Uchida, M., and Tada, E. 1988. Mode of antifungal action and selectivity of flutolanil. Agric. Biol. Chem. 52:1445-1449.
34. Nelson, B., Helms, T., Christianson, T., and Kural, I. 1996. Characterization and pathogenicity of Rhizoctonia from soybean. Plant Dis. 80:74-80.

35. Ogoshi, A. 1987. Ecology and pathogenicity of anastomosis and intraspecific groups of Rhizoctonia solani Kühn. Annu. Rev. Phytopathol. 25:125-143.

36. Ohkura, M., Abawi, G. S., Smart, C. D., and Hodge, K. T. 2009. Diversity and aggressiveness of Rhizoctonia solani and Rhizoctonia-like fungi on vegetables in New York. Plant Dis. 93:615-624.

37. Panella, L. 1998. Screening and utilizing beta genetic resources with resistance to Rhizoctonia root rot and Cercospora leaf spot in a sugar beet breeding programme. Pages 66-72 in: 4th Int. Beta Genetics Resources Workshop and World Beta Network Conf. L. Frese, L. Panella, H. M. Srivastava, and W. Lange eds. International Plant Genetic Resources Institute, Rome.

38. Panella, L., and Ruppel, E. G. 1996. Availability of germplasm for resistance against Rhizoctonia spp. Pages 515-527 in: Rhizoctonia Species: Taxonomy, Molecular Biology, Ecology, Pathology and Disease Control. B. Sneh, S. Jabaji-Hare, S. Neate, and G. Dijst, eds. Kluwer Academic Publishers, Dordrecht, The Netherlands.

39. Paulitz, T., and Reinertsen, S. 2005. In-furrow application of Quadris and Moncut for control of Rhizoctonia root rot in spring barley, 2004. In: Plant Disease Management Reports. The American Phytopathological Society, St. Paul, MN.

40. Pierson, V. G., and Gaskill, J. O. 1961. Artificial exposure of sugar beets to Rhizoctonia solani. J. Am. Soc. Sugar Beet Technol. 19:246-256.

41. Ruppel, E. G., Schneider, C. L., Hecker, R. J., and Hogaboam, G. J. 1979. Creating epiphytotics of Rhizoctonia root rot and evaluating for resistance to Rhizoctonia solani in sugarbeet field plots. Plant Dis. Rep. 63:518-522.

42. Rush, C. M., and Winter, S. R. 1990. Influence of previous crops on Rhizoctonia root and crown rot of sugar beet. Plant Dis. 74:421-425.

43. Salazar, O., Julian, M. C., and Rubio, V. 2000. Primers based on specific rDNA-ITS sequences for PCR detection of Rhizoctonia solani, $R$. solani AG 2 subgroups and ecological types, and binucleate Rhizoctonia. Mycol. Res. 104:281-285.

44. Scholten, O. E., Panella, L. W., De Bock, T. S. M., and Lange, W. 2001. A greenhouse test for screening sugar beet (Beta vulgaris) for resistance to Rhizoctonia solani. Eur. J. Plant Pathol. 107:161-166.

45. Secor, G., Rivera, V., and Khan, M. 2007. Sensitivity of Cercospora beticola to foliar fungicides in 2007. Sugarbeet Res. Ext. Rep. 38:220230.

46. Smiley, R. W. 2009. Water and temperature parameters associated with winter wheat diseases caused by soilborne pathogens. Plant Dis. 93:7380.

47. Smiley, R. W., and Uddin, W. 1993. Influence of soil temperature on Rhizoctonia root rot $(R$. solani AG-8 and $R$. oryzae) of winter wheat. Phytopathology 83:777-785.

48. Sneh, B., Burpee, L., and Ogoshi, A. 1991. Identification of Rhizoctonia Species. American Phytopathological Society Press, St. Paul, MN.

49. Sneh, B., Jabaji-Hare, S., Neate, S., and Dijst, G., eds. 1996. Rhizoctonia Species: Taxonomy, Molecular Biology, Ecology, Pathology and Disease Control. Kluwer Academic Publishers, Dordrecht, The Netherlands.

50. Stump, W. L., Franc, G. D., Harveson, R. M., and Wilson, R. G. 2004. Strobilurin fungicide timing for Rhizoctonia root and crown rot suppression in sugarbeet. J. Sugar Beet Res. 41:17-38.

51. Teo, B. K., Yitbarek, S. M., Verma, P. R., and Morral, R. A. A. 1988. Influence of soil moisture, seeding date, and Rhizoctonia solani isolates (AG 2-1 and AC 4) on disease incidence and yield in canola. Can. J. Plant Pathol. 10:151-158.

52. Windels, C. E., and Brantner, J. R. 2002. Timing applications of Quadris for control of Rhizoctonia on sugarbeet. Sugarbeet Res. Ext. Rep. 33:182195.

53. Windels, C. E., and Brantner, J. R. 2005. Early-season application of azoxystrobin to sugarbeet for control of Rhizoctonia solani AG 4 and AG 2-2. J. Sugar Beet Res. 42:1-17.

54. Windels, C. E., Jacobsen, B. J., and Harveson, R. M. 2009. Rhizoctonia root and crown rot. Pages 33-36 in: Compendium of Beet Diseases and Pests. R. M. Harveson, L. E. Hanson, and G. L. Hein, eds. American Phytopathological Society Press, St. Paul, MN.

55. Windels, C. E., and Nabben, D. J. 1989. Characterization and pathogenicity of anastomosis groups of Rhizoctonia solani isolated from Beta vulgaris. Phytopathology 79:83-88.

56. Yang, X. B., Berggren, G. T., and Snow, J. P. 1990. Types of Rhizoctonia foliar blight on soybean in Louisiana. Plant Dis. 74:501-504. 